\begin{tabular}{|l|l|l||}
\hline \multicolumn{2}{|c|}{ PublisherInfo } \\
\hline \hline PublisherName & $:$ & BioMed Central \\
\hline \hline PublisherLocation & $:$ & London \\
\hline \hline PublisherImprintName & $:$ & BioMed Central \\
\hline \hline
\end{tabular}

\title{
OptIPuter boots up
}

\begin{tabular}{|l|l|l||}
\hline \multicolumn{2}{|c||}{ ArticleInfo } \\
\hline \hline ArticleID & $:$ & 4604 \\
\hline \hline ArticleDOI & $:$ & $10.1186 /$ gb-spotlight-20021008-03 \\
\hline \hline ArticleCitationID & $:$ & gb-spotlight-20021008-03 \\
\hline \hline ArticleSequenceNumber & $:$ & 270 \\
\hline \hline ArticleCategory & $:$ & Research news \\
\hline \hline ArticleFirstPage & $:$ & 1 \\
\hline \hline ArticleLastPage & $:$ & 3 \\
\hline \hline & & RegistrationDate : 2002-10-8 \\
ArticleHistory & $:$ & OnlineDate \\
\hline \hline ArticleCopyright & $:$ & BioMed Central Ltd2002-10-8 \\
\hline \hline ArticleGrants & $:$ & \\
\hline \hline ArticleContext & $:$ & 130593311 \\
\hline \hline
\end{tabular}


A National Science Foundation (NSF) grant of $\$ 13.5$ million announced September 25 will provide five years' funding aimed at solving the problem of sharing ultra-large data sets and processor-intensive visualization applications among long-distance collaborators. "OptIPuter" - a portmanteau for "Optical networking, internet protocol, and computer storage and processing" - is a project already in development, and itself a collaboration among institutions led by the University of California, San Diego (UCSD) and University of Illinois, Chicago (UIC). Their goal is to ease exchanging and managing the enormous amounts of data becoming common in an increasing number of scientific fields.

"The chunks of data are so big that trying to get them across the shared Internet is just not possible," explained Larry Smarr, director of the California Institute for Telecommunications and Information Technology (Cal-(IT) $)^{2}$, and professor of computer science and engineering at UCSD's Jacobs School of Engineering. According to Smarr, even the high-speed academic Internet II/Abilene project is not an adequate solution. "A gigabyte of data over a gigabit Ethernet [network], pretty much, QED, cannot be done," he told The Scientist.

And once data arrives, said Smarr, there's another related problem: "If this flood of data comes to your lab, where exactly are you going to drop it?" OptIPuter provides a virtual storage area in the form of storage networks, Smarr explained. In essence, it will use the speed of optical networks and the architecture of distributed computing to create a virtual computer that researchers can call upon when necessary.

Similar distributed computing projects provide access to supercomputing power and storage, but OptIPuter developers say their network will also offer next-generation bandwith provisioning, which will allow long-distance collaborators to work together in real time, for example, on a massive image file.

Once it's up and running, life scientists will benefit from a new tool that allows them to explore much larger multi-scaled data unconstrained by bandwidth limitations, predicts co-principal investigator Mark Ellisan, a professor of neurosciences and bioengineering at UCSD and director of the university's Computational Center for MacroMolecular Structures as well as director of its National Center for Microscopy and Imaging Research.

Ellisan's lab, along with that of John Orcutt, deputy director of UCSD's Scripps Institution of Oceanography, will serve as testbeds, providing feedback to OptIPuter developers. The plan, said Ellisan, is "to take living laboratories that are pushing the envelope and connect high-data rate instruments into the lambda-enabled environment [the optical network] to experiment with the things we couldn't do before."

Smarr sees the OptIPuter is an obvious outgrowth of the new needs of experimentalists. "There's a shift to data-intensive science, in which the scientific constituency is vastly larger than it was ten years ago when supercomputers alone were enough for the needs of theorists. We now have more scientists who need more powerful bandwidth, when we once had fewer scientists who needed more powerful computers." 


\section{References}

1. National Science Foundation, [http://www.nsf.gov/]

2. University of California, San Diego, [http://www.ucsd.edu]

3. University of Illinois, Chicago, [http://www.uic.edu/]

4. California Institute for Telecommunications and Information Technology, [http://www.calit2.net/]

5. Jacobs School of Engineering, [http://www.soe.ucsd.edu/]

6. M. Cross, "UK e-Science Grid goes live," The Scientist, September 10, 2002., [http://www.thescientist.com/news/20020910/04/]

7. Computational Center for MacroMolecular Structures, [http://www.sdsc.edu/CCMS/]

8. National Center for Microscopy and Imaging Research, [http://www-ncmir.ucsd.edu/]

9. Scripps Institution of Oceanography, [http://sio.ucsd.edu/] 